\title{
How can we better identify patients with rectal bleeding who are at high risk of colorectal cancer? An observational study
}

\author{
Kieran Purich ${ }^{1,2}$ (I) Yiling Zhou ${ }^{3} \cdot$ Shawn Dodd ${ }^{1,2} \cdot$ Yan Yuan $^{3} \cdot$ Jonathan White ${ }^{1,2}$ \\ Accepted: 3 November 2021 / Published online: 16 November 2021 \\ (c) The Author(s), under exclusive licence to Springer-Verlag GmbH Germany, part of Springer Nature 2021
}

\begin{abstract}
Purpose Rectal bleeding is a common symptom of colorectal cancer. In this paper, we describe and evaluate the operation of a central access and triage system for patients with rectal bleeding, which uses a "high-risk"/ "low-risk" designation based on the referring doctor's subjective designation and a 10-item symptom checklist.

Methods A total of 1846 patients, referred between February 1, 2016, and December 31, 2018, were included. Exclusion criteria were the following: incorrect patient identification number, duplicate records, and pre-diagnosed gastrointestinal cancer. Data was obtained by chart review. Sensitivity, specificity, and positive and negative predictive values were calculated for each item on the symptom checklist.

Results Eight hundred seventy-nine (48\%) patients received endoscopy, and $37(2 \%)$ were found to have cancer. Five hundred eighty-two (32\%) patients were deemed high-risk. Twenty-nine (78\%) of the patients with cancer were in the high-risk group. Patients in the high-risk group had a higher incidence of cancer $(5.0 \%$ vs $0.6 \%, p<0.001)$ and shorter waits to endoscopy (201 vs 292 days). Patients designated as high-risk by the referring physician had a relative risk of 22.3 compared to those designated as low-risk. Patients deemed high-risk by the symptom checklist had a relative risk of 3.5 compared to low-risk patients. Conclusion Our system stratified 29/37 (78\%) of the patients found to have cancer as high-risk. A total of 8/37 (22\%) patients with cancer were deemed low-risk. Our research has identified two variables (weight loss and anemia) which have been added to our referral symptom checklist. This study helped us identify areas for refinement of our triage system. These findings are of interest to physicians who treat colorectal cancer.
\end{abstract}

Keywords Colorectal $\cdot$ Adenocarcinoma $\cdot$ Rectal bleeding $\cdot$ Access to care $\cdot$ Endoscopy $\cdot$ Triage

\section{Introduction}

Colorectal cancer is one of the most common malignancies affecting Canadians [1]. It is believed that the majority of colorectal carcinomas develop slowly, through the

This research was presented at the University of Alberta's Tom Williams Research Day on May 14, 2021 and as a poster at the 2021 Canadian Surgery Forum from September 21-24, 2021.

Kieran Purich

kpurich@ualberta.ca

1 Department of Surgery, University of Alberta Faculty of Medicine and Dentistry, c/o Dvorkin Lounge Mailroom, 2G2 Walter C. Mackenzie Health Sciences Centre, 8440 112 ST NW, Edmonton, AB, Canada

2 Faculty of Medicine and Dentistry, University of Alberta, Edmonton, AB, Canada

3 School of Public Health, University of Alberta, Edmonton, $\mathrm{AB}$, Canada adenoma-carcinoma pathway, as described by Fearon and Vogelstein in 1990 [2-4]. This is thought to occur over a period of years and allows time for preventative screening programs for colorectal cancer to identify and treat these lesions at an early stage. Despite this, individuals continue to present with late, incurable disease [5, 6]. In Alberta, data from 2016 to 2017 suggested that $22 \%$ of individuals with colon cancer had stage 4 disease at diagnosis, and similar trends are seen across Canada [1,7]. The reasons for this are likely multifactorial; however, once patients present to care with concerning signs and symptoms, such as rectal bleeding, anemia or altered bowel habits, it is important to have accurate triage methods to obtain an appropriate diagnosis in a timely manner [8,9]. Rectal bleeding, the focus of our study, is also commonly observed in patients with benign pathologies, making it difficult to decide which patients with rectal bleeding require endoscopic investigation [10]. This will be especially relevant when dealing with the backlog of patients requiring care after the global COVID-19 pandemic. 
The Facilitated Access to Surgical Treatment (FAST) program is a centralized referral system introduced in Edmonton, Alberta, in 2015 to improve outpatient access to surgical care. Since then, the program has received over 30,000 referrals for a variety of general surgical conditions, including rectal bleeding. Referring physicians are required to identify the main reason for referral and provide supporting information, including a narrative referral letter.

The aim of this study was to evaluate the incidence of colorectal cancer in our population and to examine the performance of our current triage system for patients referred with rectal bleeding and to identify areas for improvement. We hypothesize that our current system is able to stratify individuals into high and low-risk groups with high accuracy. We report and discuss the incidence of cancer and polyps in our high- and low-risk patient groups and evaluate the accuracy of our triage methods to predict the presence of colorectal cancer.

\section{Methods}

\section{Population}

We performed an analysis of all consecutive patients referred with rectal bleeding to the FAST program (located at the Royal Alexandra Hospital in Edmonton, Alberta, Canada) between the dates of February 1, 2016, and December 31, 2018. We followed the STROBE guidelines for the reporting of observational studies [11]. After institutional ethics approval, we obtained referral data from the FAST office. Allowing a minimum of 1 year of lag time from the final included referral, data was obtained by the study team from a local electronic medical record system. Data extraction was completed by a surgical resident and a senior medical student (KP and SD). Exclusion criteria included errors in the patient identification number on the provided referrals, duplicate referrals within the study period (in which only the first referral was included), and if the patient had a recently diagnosed gastrointestinal malignancy at
Fig. 1 Inclusion and exclusion diagram for all patients referred to the FAST program with rectal bleeding between February 2016 and December 2018. *Not all patients who had endoscopy have a first appointment date recorded. SD, referring doctors subjective designation; SC, symptom checklist

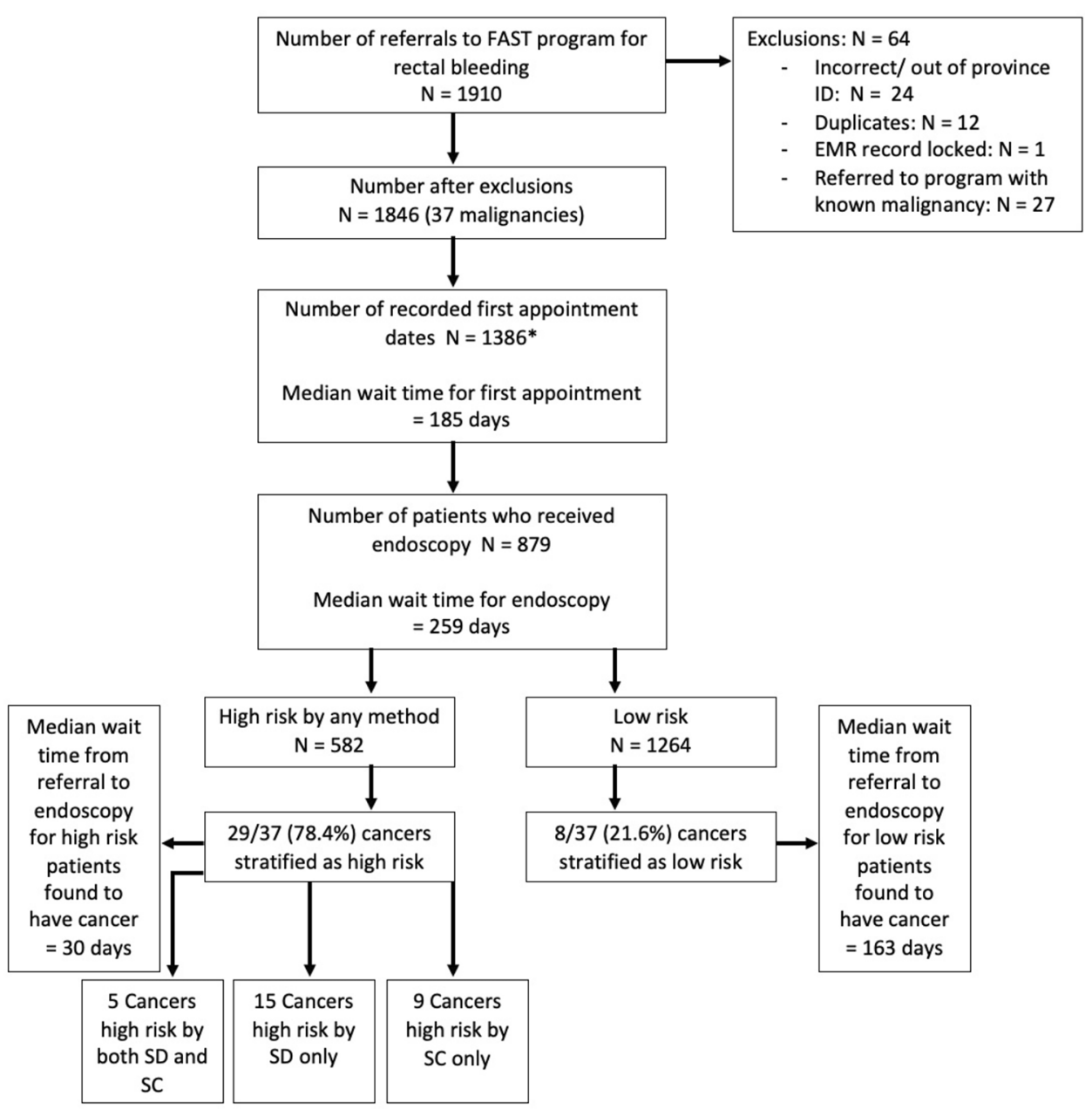


the time of referral (Fig. 1). Patients who cancelled or rescheduled their initial appointments had subsequent dates arranged by the accepting consultant directly, and their initial appointment dates are therefore not recorded; however, all endoscopic investigations and surgical interventions following initial referral dates were available.

\section{Triage criteria for patients with rectal bleeding}

Patients were separated into high- and low-risk groups based on the results from the two forms provided by the referring physician:

1. Initial risk designation by family doctor. For patients with rectal bleeding, referring physicians were required to state on the main FAST Form if they considered the patient to be "high-risk (probable cancer)" or "low-risk (probable hemorrhoids)" (Fig. 2a).

2. Symptom checklist. For all patients with rectal bleeding, referring doctors were asked to complete a checklist of symptoms associated with rectal bleeding and the findings of a digital examination (Fig. 2b). Several of the symptoms listed here are traditionally associated with high-risk bleeding (dark blood, blood mixed with the stool, etc.). Checklists with three or more missing categories were considered incomplete and excluded from the study. Previous studies have shown that questionnaires used to risk stratify patients for colon cancer can result in reproducible, accurate triage results [12].

There were two ways in which a patient could be designated as high-risk: "high-risk" indicated on the main FAST Form (regardless of the symptom checklist) or at least one high-risk symptom noted on the symptom checklist (regardless of the risk designation on the main form). These highrisk patients were assigned to see a surgeon without delay.

Patients designated as "low-risk" who also had no highrisk symptoms on the checklist were assigned to a Low-Risk Rectal Bleeding Screening Clinic for assessment by a family doctor with an interest in colorectal cancer care.

\section{Clinical outcomes}

A local electronic medical record (EMR) was searched in a reproducible fashion and provided detailed information on procedures, biopsy, and pathology results. Patient age, sex, endoscopic history, and pathology results were recorded. The presence of cancer and premalignant and benign (hyperplastic) polyps were confirmed by pathology. The presence of hemorrhoids was obtained from endoscopy reports. A full chart review was performed on patients who were deemed low-risk but were later found to have cancer to identify areas for our current system to improve. a.

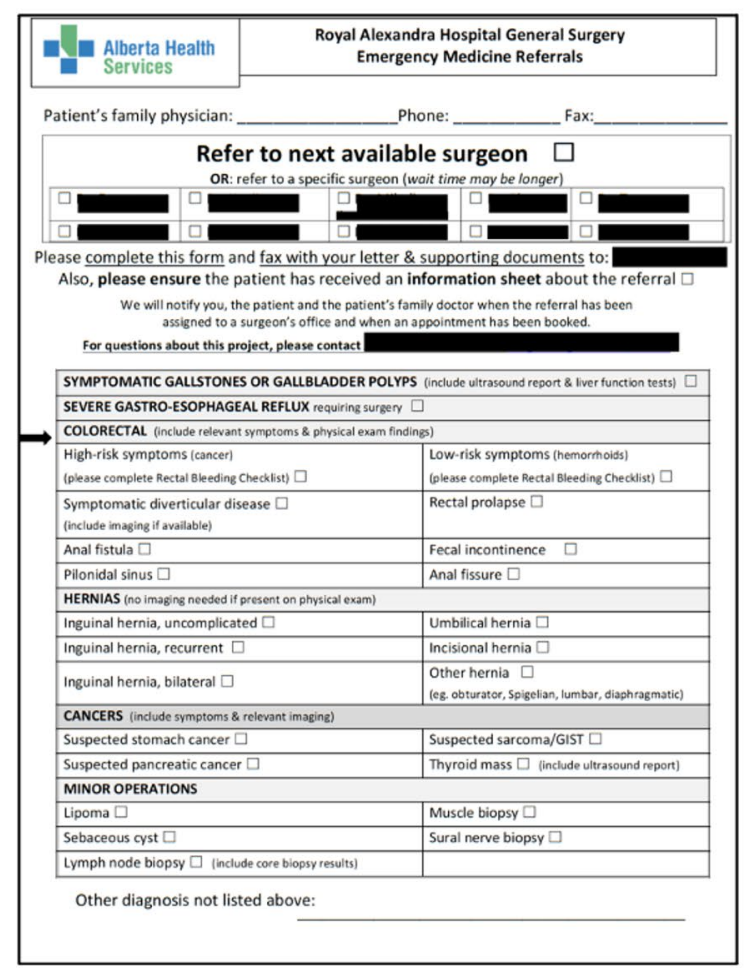

b.

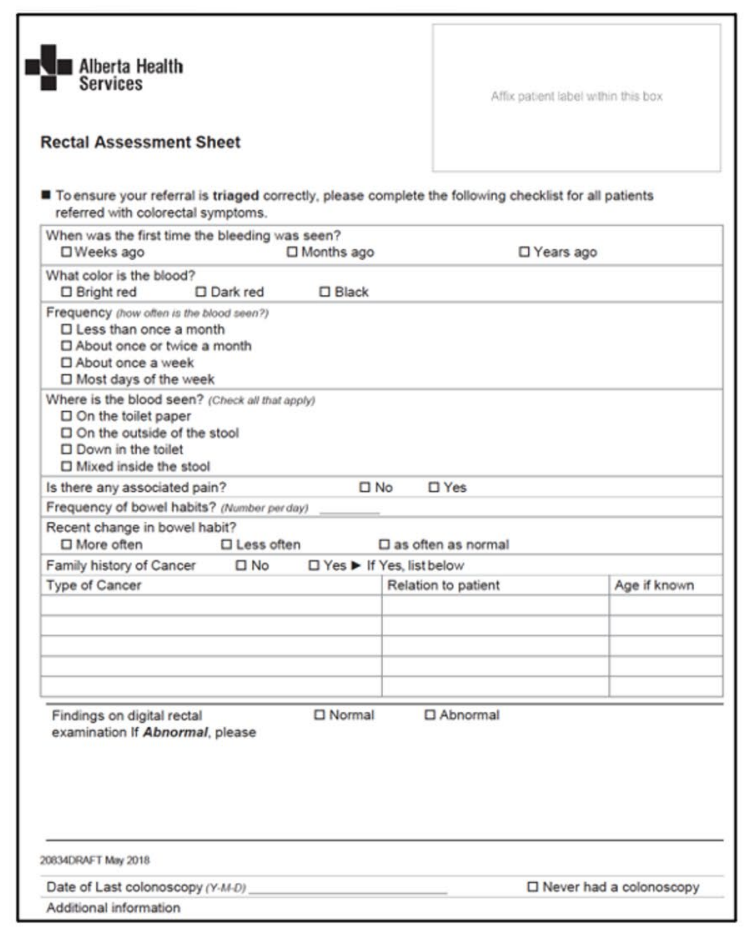

Fig. 2 Triage forms for patients referred with rectal bleeding. a The Facilitated Access to Surgical Treatment (FAST) Program's FAST Form. Physician names have been blacked out for the purpose of publication. Black arrow indicates section pertinent to patients with rectal bleeding. b The FAST Program's symptom checklist. Utilized from February 2016 to December 2018 


\section{Quantitative data analysis}

We calculated the sensitivity, specificity, and positive and negative predictive values for each item in the symptom checklist, their composite score, and the classification from the referral physician on the FAST Form with respect to cancer classification. Proportions of malignant and premalignant lesions diagnosed in high- and low-risk groups stratified by different instruments were compared using the chi-square test. $P$ values of $\leq 0.05$ were considered to be statistically significant. Positive predictive values (PPVs) were compared to the overall chance of a patient chosen from our population at random to be diagnosed with cancer. To evaluate how well our triage system predicts malignant or premalignant disease, we used a logistic regression with the least absolute shrinkage and selection operator (LASSO) analysis for variable selection. Cross-validated risk estimates were used to construct a receiver operating characteristic (ROC) curve and used to assess the overall discriminatory power of our triage system. All analyses were completed with R statistical analysis software, version 4.0.4 [13].

\section{Methods to address bias}

To minimize bias in our study, we included consecutive patients and applied well defined inclusion/exclusion criteria. Authors with medical knowledge obtained data firsthand from an up-to-date clinical database. All patients referred during the time frame with rectal bleeding were accounted for. We are transparent with the limitations of the incomplete symptom checklists.

\section{Results}

\section{Descriptive results}

A total of 1910 patients with rectal bleeding were referred to the FAST program. Sixty-four patients were excluded due to the following: incorrect patient identification numbers, duplicate referrals, locked confidential charts, and gastrointestinal (GI) cancer being recently diagnosed (Fig. 1). Table 1 outlines the descriptive statistics of the 1846 patients that were included in the study. In total, 1386 (75\%) of these patients have recorded primary appointment dates.

The study population had a median age of $51.0,52 \%$ were female, and $879(48 \%)$ received lower gastrointestinal (GI) investigation following referral. Approximately half of our patients $(967 / 1846,52 \%)$ did not receive endoscopy for a variety of reasons including the following: previous recent endoscopic investigation, resolution of rectal bleeding, and patient refusal. Colonoscopy was the most common type of investigation with 800 (43\%) patients receiving such. The median wait
Table 1 Descriptive statistics for all patients assessed by the FAST program for rectal bleeding $(n=1846)$

\begin{tabular}{|c|c|c|c|}
\hline & $\begin{array}{l}\text { Low risk } \\
(N=1264)\end{array}$ & $\begin{array}{l}\text { High risk } \\
(N=582)\end{array}$ & $\begin{array}{l}\text { Overall } \\
(N=1846)\end{array}$ \\
\hline \multicolumn{4}{|l|}{ Age } \\
\hline $\operatorname{Median}\left(Q_{1}, Q_{3}\right)$ & $51.0(39.0,62.0)$ & $52.0(40.0,64.0)$ & $51.0(39.0,63.0)$ \\
\hline \multicolumn{4}{|l|}{ Sex } \\
\hline Female & $655(51.8 \%)$ & $311(53.4 \%)$ & $966(52.3 \%)$ \\
\hline Received endoscopy & $538(42.6 \%)$ & $341(58.6 \%)$ & $879(47.6 \%)$ \\
\hline \multicolumn{4}{|l|}{ Endoscopy type post-referral } \\
\hline Colonoscopy & $482(38.1 \%)$ & $318(54.6 \%)$ & $800(43.3 \%)$ \\
\hline Other investigation & $56(4.4 \%)$ & $23(4.0 \%)$ & $79(4.3 \%)$ \\
\hline $\begin{array}{l}\text { No investigation but colonoscopy } \\
\text { in the past } 10 \text { years }\end{array}$ & $196(15.5 \%)$ & $56(9.6 \%)$ & $252(13.7 \%)$ \\
\hline None & $530(41.9 \%)$ & $185(31.8 \%)$ & $715(38.7 \%)$ \\
\hline Malignancy & $8(0.6 \%)$ & $29(5.0 \%)$ & $37(2.0 \%)$ \\
\hline Premalignancy & $139(11.0 \%)$ & $103(17.7 \%)$ & $242(13.1 \%)$ \\
\hline \multicolumn{4}{|l|}{ Days to 1st appointment } \\
\hline $\operatorname{Median}\left(Q_{1}, Q_{3}\right)$ & $209(127,294)$ & $136(47,247)$ & $185(105,284)$ \\
\hline \multicolumn{4}{|l|}{ Days to endoscopy } \\
\hline $\operatorname{Median}\left(Q_{1}, Q_{3}\right)$ & $292(190,448)$ & $201(77,383)$ & $259(136,426)$ \\
\hline \multicolumn{4}{|c|}{ Diagnoses for all patients who received endoscopy } \\
\hline & $\begin{array}{l}\text { Low risk } \\
(N=538)\end{array}$ & $\begin{array}{l}\text { High risk } \\
(N=341)\end{array}$ & $\begin{array}{l}\text { Overall } \\
(N=879)\end{array}$ \\
\hline Hemorrhoids & $397(73.9 \%)$ & $232(68.0 \%)$ & $629(71.6 \%)$ \\
\hline Polyps & $195(36.3 \%)$ & $154(45.2 \%)$ & $349(39.7 \%)$ \\
\hline Malignancy & $8(1.5 \%)$ & $29(8.5 \%)$ & $37(4.2 \%)$ \\
\hline
\end{tabular}


time to endoscopy for patients deemed high-risk was 201 days, compared to 292 days for low-risk (Table 1). Almost one-third of patients $(582 / 1846,32 \%)$ were classified as high-risk by either method (initial designation or symptom checklist), while two-thirds (1264/1846, 68\%) were classified as low-risk.

Thirty-seven patients out of 1846 were diagnosed with cancer (2\%). Twenty-nine of the 582 patients categorized as high-risk were diagnosed with cancer (5\%). Eight of the 1264 patients categorized as low-risk were diagnosed with cancer $(0.6 \%)$ (relative risk $(R R)=7.9, p<0.001$ (Tables 1 and 2)). As is demonstrated in Table 2, patients classified as high-risk by any method had a greater risk of cancer compared to those classified as low-risk.

The median time from referral date to the diagnosis of cancer was 30 days for high-risk patients versus 163 days for low-risk (Fig. 1). Details regarding the age and sex of patients diagnosed with malignancy can be seen in Table 3 . As would be expected, most cancers $(30 / 37,81 \%)$ were in the $>60$-year-old age group. A total of $18 \%$ and $11 \%$ of patients were identified to have premalignant polyps in the high- and low-risk groups, respectively. Seventy-two percent of patients who received endoscopy were diagnosed with hemorrhoids (Table 1 ).

Of the 37 cancers, 16 (43\%) were colon cancer, $13(35 \%)$ were rectal cancer, five (14\%) were anal cancer, and three patients (8\%) had other GI malignancies. Of the 29 patients with colon or rectal cancer, seven (24\%) were stage 4, eight (28\%) were stage 3 , eight (28\%) were stage 2, three (10\%) were stage 1 , two (7\%) were stage 0 (malignancy within a polyp), and one (3\%) patient did not get staging investigations or subsequent management (Fig. 3).

Table 2 Incidence of malignant and premalignant lesions diagnosed in high and low risk groups when stratified by different triage methods

\begin{tabular}{|c|c|c|c|c|}
\hline & Low risk & High risk & Overall & p value \\
\hline \multicolumn{5}{|c|}{ All patients $(N=1846)$} \\
\hline Premalignant only & $136(10.8)$ & $93(16.0)$ & $229(12.4)$ & 0.002 \\
\hline Malignant & $8(0.6)$ & $29 *(5.0)$ & $37(2.0)$ & $<0.001$ \\
\hline $\begin{array}{l}\text { Premalignant or } \\
\text { malignant }\end{array}$ & $144(11.4)$ & $\begin{array}{l}122 \\
(21.0)\end{array}$ & $266(14.4)$ & $<0.001$ \\
\hline \multicolumn{5}{|c|}{ FAST Form $(N=1811)$} \\
\hline Premalignant only & $212(12.4)$ & $16(16.7)$ & $228(12.6)$ & 0.216 \\
\hline Malignant & $16(0.9)$ & $20(20.8)$ & $36(1.9)$ & $<0.001$ \\
\hline $\begin{array}{l}\text { Premalignant or } \\
\text { malignant }\end{array}$ & $228(13.3)$ & $36(34.5)$ & $264(14.5)$ & $<0.001$ \\
\hline \multicolumn{5}{|c|}{ Symptom checklist $(N=1290)$} \\
\hline Premalignant only & 89 (11.5) & $84(16.2)$ & $173(13.4)$ & 0.019 \\
\hline Malignant & $6(0.8)$ & $14(2.7)$ & $20(1.6)$ & 0.012 \\
\hline $\begin{array}{l}\text { Premalignant or } \\
\text { malignant }\end{array}$ & $95(12.3)$ & $98(18.9)$ & $193(15.0)$ & 0.011 \\
\hline
\end{tabular}

*Five patients found to have cancer were deemed high risk by both the FAST Form and the Symptom Checklist
Table 3 Descriptive statistics for patients diagnosed with malignancy

\begin{tabular}{|c|c|c|c|}
\hline & \multicolumn{3}{|c|}{ Proportion with cancer (\%) } \\
\hline & $\begin{array}{l}\text { Female } \\
(N=966)\end{array}$ & $\begin{array}{l}\text { Male } \\
(N=880)\end{array}$ & $\begin{array}{l}\text { All patients } \\
(N=1846)\end{array}$ \\
\hline \multicolumn{4}{|c|}{ Age (years) } \\
\hline$<40$ & $0 / 256(0 \%)$ & $0 / 208(0 \%)$ & $0 / 464(0 \%)$ \\
\hline $40-59$ & $4 / 392(1.0 \%)$ & $3 / 400(0.8 \%)$ & $7 / 792(0.9 \%)$ \\
\hline$\geq 60$ & $14 / 318(4.4 \%)$ & $16 / 272(5.8 \%)$ & $30 / 590(5.1 \%)$ \\
\hline All ages & $18 / 966(1.9 \%)$ & $19 / 880(2.2 \%)$ & $37 / 1846(2.0 \%)$ \\
\hline
\end{tabular}

\section{Impact of initial risk designation by family doctor}

In total, 1811 (98\%) patients and 36 of the 37 (97\%) patients diagnosed with cancer had the FAST Form complete. Descriptive statistics are provided in Supplemental Table 1. Ninety-six (5\%) patients were deemed high-risk by the FAST Form, and 73 (76\%) of this group received lower GI investigation, compared to $792 / 1715$ (46\%) in the low-risk group. Twenty patients (21\%) in the high-risk group were diagnosed with cancer, and 24 (25\%) were diagnosed with premalignant lesions. In the low-risk group, $16(0.9 \%)$ and $217(13 \%)$ were diagnosed with cancer and premalignancy, respectively (relative risk for the high-risk cancer group in comparison to the low-risk cancer group was 22.3, $p<0.001$; Table 2; Supplemental Table 1). This means that patients designated as high-risk by their family doctor were 22 times more likely to have cancer than those designated as low-risk, regardless of other information provided. The median time from referral to endoscopy was 57 and 274 days in the high- and low-risk groups, respectively.

\section{Impact of the symptom checklist}

The symptom checklist was completed for 1290 (70\%) patients. Descriptive statistics are provided in Supplemental Table 2. Five hundred eighteen (40\%) patients with the symptom checklist complete were classified as highrisk. Two hundred ninety-two (56\%) of high-risk patients received investigation in comparison to $343(44 \%)$ of the low-risk group. Fourteen (3\%) patients in the high-risk group and $6(0.8 \%)$ in the low-risk group were diagnosed with malignancy $(R R=3.5)$. This means that patients designated as high-risk by the checklist were 3.5 times more likely to have cancer than those designated as low-risk. Eighty-nine (17\%) patients in the high-risk group and 92 (12\%) patients in the low-risk group were diagnosed with premalignant lesions. The median time from referral to endoscopy, for the patients who received endoscopic investigation, was 219 days in the high-risk group vs 323 days in the low-risk group. 
Fig. 3 Type of malignancy and its association with risk stratification across subgroups and risk stratification methods. a Type of cancer diagnosed $(n=37)$. b TNM stage for patients diagnosed with colorectal cancer $(n=29)$. $\mathbf{c}$ TNM stage for patients with colorectal cancer deemed low risk $(n=6)$. d TNM stage for patients with colorectal cancer deemed high risk $(n=23)$. e Analysis of the risk stratification relationships between the FAST Form and symptom checklist in the entire study population $(n=1846)$. $\mathbf{f}$ Analysis of the risk stratification relationships between the FAST Form and symptom checklist in patients who were found to have malignancies $(n=37)$

TYPE OF CANCERS DIAGNOSED IN STUDY POPULATION

a.

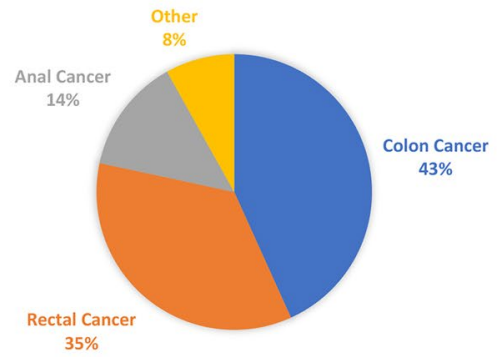

TNM STAGE FOR PATIENTS WITH COLORECTAL CANCER c.
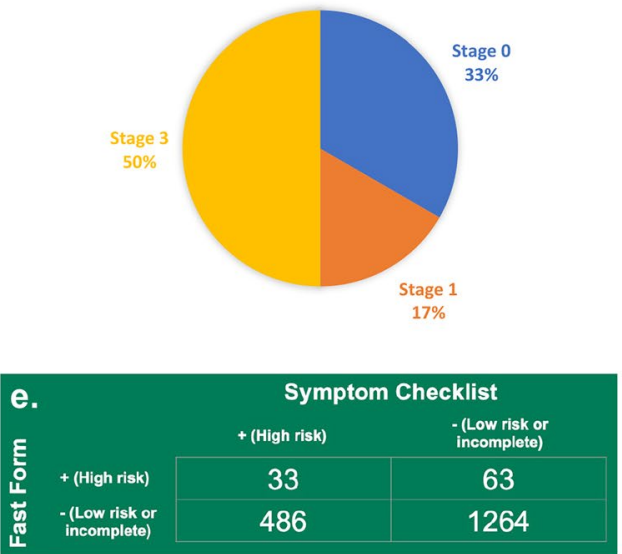

TNM STAGE FOR PATIENTS WITH COLORECTAL CANCER

b.

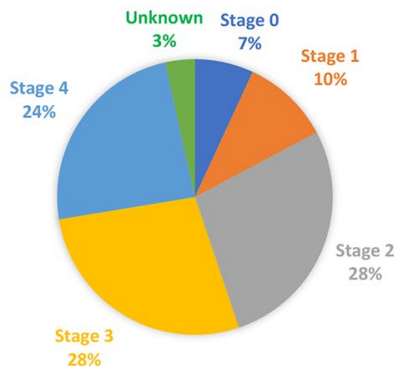

TNM STAGE FOR PATIENTS WITH COLORECTAL CANCER

d.

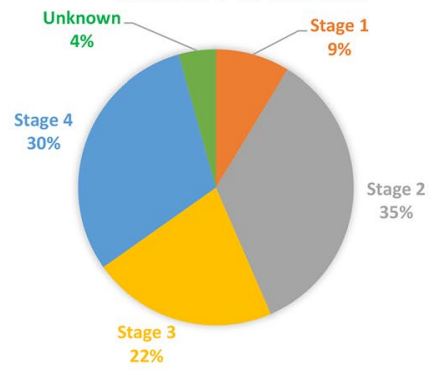

\section{Agreement between family doctor designation and the symptom checklist}

For the two instruments we used, there was concordance in $70 \%$ of cases (1297/1846, 33 high-risk and 1264 low-risk). In 486 cases (26\%), the checklist contained at least 1 highrisk symptom, but the designation given by the family doctor was low-risk; these patients were treated as high-risk. In 63 (3\%) cases, the FAST Form indicated the patient was highrisk, but there were no high-risk symptoms on the checklist; these patients were treated as high-risk.

This discordance was also observed in the patients diagnosed with cancer. Five (14\%) cases were designated as high-risk on both instruments, and in 24 (65\%) cases, there was discordance: nine (24\%) with high-risk symptoms but a low-risk designation by the referring provider, and $15(41 \%)$ with a high-risk designation but no high-risk symptoms. Concerningly, in eight (22\%) patients later diagnosed with cancer, both instruments indicated low-risk status (Fig. 3e, f).

\section{Accuracy of the symptom checklist in the detection of cancer}

A summary of the data obtained from the symptom checklist can be seen in Table 4. Overall, due to the rarity of cancer in our population, the sensitivities for separate symptoms are low and the negative predictive values are uniformly high. Looking at the features, we use to stratify individuals as high-risk, these being dark red or black blood, blood mixed in with the stool, altered bowel habits, or a significant family history of colorectal cancer (as defined by two or more first degree relatives with colorectal cancer or a relative with colorectal cancer before 60 years of age); we can see that 4 of the 5 top PPVs (black blood $=5.56$, blood mixed in the stool $=3.02$, more frequent or less frequent bowel movements $=3.16$ and 2.65 , respectively) were criteria for highrisk designation as deemed by our triage protocol. The fifth symptom used to decide on high-risk stratification was dark red blood, which was found to have a PPV of 1.59. This is below the overall incidence of cancer in our referral population $37 / 1846(2.0 \%)$, indicating that patients with the presence of dark red blood on symptom checklist are less likely to be diagnosed with cancer than patients drawn at random from our study population.

\section{Results of digital rectal exams on the symptom checklist}

In total, $1153 / 1290(89 \%)$ patients had the results of a digital rectal exam documented on the checklist. In total, 103/1290 
Table 4 The accuracy of symptoms on the symptom checklist for the prediction of the presence of malignancy

\begin{tabular}{|c|c|c|c|c|c|}
\hline & $\begin{array}{l}\text { Number of } \\
\text { patients with } \\
\text { symptom } \\
(\mathbf{N}=1290)\end{array}$ & $\begin{array}{l}\text { Positive } \\
\text { predictive } \\
\text { value }(\%)\end{array}$ & $\begin{array}{l}\text { Negative } \\
\text { predictive } \\
\text { value }(\%)\end{array}$ & $\begin{array}{l}\text { Sensitivity } \\
(\%)\end{array}$ & $\begin{array}{l}\text { Specificity } \\
(\%)\end{array}$ \\
\hline \multicolumn{6}{|l|}{ First seen } \\
\hline Weeks & 330 & 1.82 & 98.54 & 30.00 & 74.49 \\
\hline Months & 437 & 2.52 & 98.94 & 55.00 & 66.46 \\
\hline Years & 489 & 0 & 97.50 & 0 & 61.50 \\
\hline \multicolumn{6}{|l|}{ Color } \\
\hline Bright red & 1103 & 1.45 & 97.86 & 80.00 & 14.41 \\
\hline Dark red & 126 & 1.59 & 98.45 & 10.00 & 90.24 \\
\hline Black & 18 & 5.56 & 98.51 & 5.00 & 98.66 \\
\hline \multicolumn{6}{|l|}{ Bleeding frequency } \\
\hline Less than once a month & 255 & 1.57 & 98.45 & 20.00 & 80.24 \\
\hline About once or twice a month & 291 & 0.34 & 98.10 & 5.00 & 77.17 \\
\hline About once a week & 242 & 2.48 & 98.66 & 30.00 & 81.42 \\
\hline Most days of the week & 469 & 1.71 & 98.54 & 40.00 & 63.70 \\
\hline \multicolumn{6}{|l|}{ Blood location } \\
\hline On the toilet paper & 303 & 1.98 & 98.58 & 30.00 & 76.61 \\
\hline Outside of stool & 211 & 0.95 & 98.33 & 10.00 & 83.54 \\
\hline Down in toilet & 540 & 0.93 & 98.00 & 25.00 & 57.87 \\
\hline Mixed inside the stool & 232 & 3.02 & 98.77 & 35.00 & 82.28 \\
\hline \multicolumn{6}{|l|}{ Pain } \\
\hline No pain & 724 & 1.52 & 98.41 & 55.00 & 43.86 \\
\hline Yes, pain present & 548 & 1.64 & 98.52 & 45.00 & 57.56 \\
\hline \multicolumn{6}{|l|}{ Changes to bowel movements } \\
\hline No & 984 & 1.12 & 97.06 & 55.00 & 23.39 \\
\hline More often & 158 & 3.16 & 98.67 & 25.00 & 87.95 \\
\hline Less often & 113 & 2.65 & 98.56 & 15.00 & 91.34 \\
\hline \multicolumn{6}{|l|}{ Family history } \\
\hline No & 997 & 1.40 & 97.95 & 70.00 & 22.60 \\
\hline Yes & 172 & 1.74 & 98.48 & 15.00 & 86.69 \\
\hline \multicolumn{6}{|l|}{ DRE } \\
\hline No finding, normal & 565 & 1.06 & 98.07 & 30.00 & 55.98 \\
\hline Yes, abnormal & 548 & 2.19 & 98.92 & 60.00 & 57.80 \\
\hline
\end{tabular}

patients (8\%) did not have a recorded exam and 34/1290 (3\%) patients were recorded as having declined to be examined.

\section{Assessment of patients stratified as low-risk found to have cancer}

We conducted a detailed chart review of the eight patients who were classified as low-risk, but were later found to have cancer. Four of them were found to have referrals classified as incomplete, with missing data on either the FAST Form or symptom checklist. Another three had complete referrals containing no notable "red flags." The final patient had weight loss mentioned on their referral letter, but there were no high-risk features mentioned on the FAST Form or symptom checklist, and this patient was seen in an expedited fashion because of the weight loss.

\section{LASSO binary logistic regression}

To quantify our triage system's predictive ability to identify patients with cancer or premalignant disease, we used tenfold cross-validation to obtain the best tuning parameters for the LASSO method. Six symptoms from the symptom checklist were included, these being when the bleeding was first seen, the color of the blood, the presence of changes to bowel habits, changes to the overall number of daily bowel movements, the location of the blood (inside vs outside of the stool), and the presence or absence of pain. Three variables available from the FAST Form were included: age, sex, and FAST Form risk status. Due to the rarity of cancer in our population, we were unable to build a model which could be utilized for the prediction of malignant disease alone; therefore, we built a model to predict the presence 
of malignant or pre-malignant disease. The odds ratio estimates for each predictor are summarized in Supplemental Table 3. The estimated AUC of the prediction model was 0.692 (Supplemental Fig. 1). Previous studies have defined AUC values of $0.6-0.7$ as poor and $0.7-0.8$ as fair, indicating that our model demonstrates a poor overall test accuracy for the prediction of malignant and premalignant disease [14].

\section{Discussion}

This study provides valuable information on how our healthcare system provides care to patients with rectal bleeding, a common complaint which can be associated with colorectal cancer. The study is reflective of real-world practice and should resonate with practitioners who have encountered similar problems with incomplete referrals, imperfect risk classification, and long waiting times for endoscopy. It is particularly relevant in the aftermath of the global COVID-19 pandemic, which has caused much delay in presentation and referral of patients with cancer-related symptoms [15-17]. Triage systems such as the one described in our manuscript will be required to deal with the backlog associated with the pandemic.

Our findings parallel other studies which found that around $2 \%$ of patients presenting with rectal bleeding will be diagnosed with a cancer $[18,19]$. This being said, a wide variety of variable selection criteria has been used for previous studies, leading to a broad range of results as is outlined in prior review articles [20,21]. Our study population included all patients seen through our referral program, was not stratified by age, and as far as we are aware, was the first study of its kind in a Canadian healthcare system. This may explain why our value of $2 \%$ is lower than reported in some other manuscripts [12, 20, 21]. We are also in agreement with others who have reported that $20 \%$ of patients classified as high-risk/urgent priority for endoscopy will have a cancer, and that approximately $25 \%$ of patients with colon cancer will be stage IV at the time of diagnosis $[1,7,22]$. Others have also found that up to $25 \%$ of all patients will be found to have adenomatous polyps, which is comparable the numbers seen in our study [23-25]. We also recorded patients who have benign polyps, making our overall diagnoses of "polyps" greater than previously seen. These observations suggest that the findings of this study are broadly comparable to other studies with patient populations similar to those seen in Canada.

This study showed that our triage system for the management of patients presenting with rectal bleeding worked reasonably well, and that the designation of patients into high- and low-risk categories was relatively effective; patients designated as high-risk were 7.9 times more likely to have cancer as those designated as low-risk. We found that the family doctor's designation of high-risk had a greater predictive ability than the symptom checklist, with a relative risk of 22 compared to 3.5 , respectively. We found that having two ways to assess the patient's risk was more efficient than having just one. Twenty-nine of the 37 patients with cancer were correctly identified as being high-risk at the time of referral, as determined by either the referral form designation or the symptom checklist. Using the referral form only would have caught 20 of these patients and missed 17. Using the symptom checklist alone would have caught just 14 of these patients and missed 23.

It is reassuring to note that around $98 \%$ of patients in our study who presented with rectal bleeding did not have cancer. Having said that, one-third of the patients in the study were designated as being potentially at high-risk for having cancer, although only $5 \%$ of these patients ultimately received a cancer diagnosis. The challenge is therefore to accurately discriminate the small number of patients who do have cancer from a much larger number of patients who have a benign cause for their bleeding. This challenge amounts to finding the proverbial "needle in a haystack" — rapidly identifying patients who are most at risk of having cancer and ensuring that they are provided with testing to confirm or rule out a cancer diagnosis as quickly as possible. This study shows that we are some distance away from having a perfect, highly efficient system as the majority of patients designated as highrisk did not have cancer, while several patients with cancer were classified as low-risk and received a delayed diagnosis.

It is interesting to note that $1 / 5$ of patients who were ultimately diagnosed with cancer were initially assessed as being low-risk by the referring family doctor or by the symptom checklist. This is concerning as our study shows that patients assessed as being low-risk tended to have a longer waiting time for endoscopy. Several of the patients with cancer who were classified as low-risk had incomplete referrals with missing information. This emphasizes the importance of family doctors providing all relevant information at the time of referral. These results also suggest that some patients who have a colorectal cancer may not in fact have any symptoms that we would traditionally recognize as high-risk; it is possible that there may be no "perfect" way to identify all patients who are in fact at high-risk of having a cancer diagnosis.

We found that the risk designation given by the family doctor was much more effective at predicting cancer than the symptom checklist. This may indicate that family doctors stratified patients as high-risk based on the overall clinical picture, encompassing multiple clinical findings, whereas the symptom checklist is less selective and stratifies all patients with a single concerning symptom as high-risk. In the literature, prior questionnaire based studies and systematic reviews have shown that singular symptoms used in isolation are not particularly sensitive in the prediction of colorectal cancer, similar to what was seen in our patient population [10, 18, 20, 26, 27]. Previous studies have even 
suggested that due to the general and nonspecific nature of the gastrointestinal symptoms that accompany rectal bleeding, it is difficult to precisely identify all patients with colon cancer and use this information to advocate for increased patient access to lower gastrointestinal endoscopy [10]. In addition, symptom checklists and algorithms which are often used for triage purposes have been previously documented to have deficiencies in overall accuracy, leading to a greater number of medical visits and greater expenditures than what is seen with triage decisions being made by trained medical providers [28]. Our analysis confirmed that the symptoms on the checklist which are used to indicate high-risk were in fact statistically associated with cancer, but with their low positive predictive values, they were less specific for the diagnosis of cancer than the opinion of the referring physicians.

There was a high discordance between the family doctor's overall impression and the individual symptoms noted in the checklist. In many instances, the family doctor stated that the patient was high-risk, but all of the symptoms on the accompanying checklist were low-risk. In other cases, the family doctor stated that the patient was low-risk but attached a checklist that contained high-risk symptoms. More study is required to understand more about the cognitive processes of family doctors who are referring patients for a potential cancer diagnosis and to determine whether additional education about the symptoms of colorectal cancer is required.

It is common to hear surgeons complain that family doctors are reluctant to do digital rectal examinations, but this study confirms that this is simply not the case. Ninety-two percent of patients were offered a rectal examination, and $89 \%$ had one performed. We hope that this study will finally put this surgical myth to rest.

We have used the results of the study to try to improve our program and to try to provide a more accurate risk classification for patients. While it is disappointing that eight patients with cancer were initially classified as being low-risk at triage, these patients were still assigned to a see surgeon, had a complete history and physical examination performed, and received endoscopy and biopsy that led to their diagnosis. The main issue here is not the failure to diagnose cancer, but the failure to recognize high-risk symptoms leading to a delayed diagnosis, and potentially poor outcomes based on this. In response to the findings of the study, we updated our symptom checklist by adding categories for weight loss and anemia. We are also working with the referring doctors to improve the completeness of the referral package so that we can improve the evaluation of cancer risk for each patient.

In conclusion, this study shows that our central access triage program appears to work well in providing care to patients with rectal bleeding and in stratifying them into high-risk and low-risk groups for the purposes of further investigation and management. We have shown that using two methods of risk designation are better than one, and we intend to continue to work to improve our program in the aftermath of the COVID-19 pandemic. Our findings are of significant interest to general practitioners, gastroenterologists, and general surgeons involved in the referral and triage of patients presenting with rectal bleeding.

Supplementary Information The online version contains supplementary material available at https://doi.org/10.1007/s00384-021-04063-w.

Author contribution Kieran Purich and Jonathan White contributed to the study conception and design. Data collection and analysis were completed by Kieran Purich, Yiling Zhou, Shawn Dodd, and Yan Yuan. The initial manuscript was drafted by Kieran Purich. All authors revised the final manuscript and approved the final version for submission.

Funding This research received a $\$ 2000.00$ grant from the University of Alberta to assist with the costs of statistical analysis. This study was approved by the University of Alberta's Research Ethics Office, through the Health Research Ethics Board.

\section{Declarations}

Conflict of interest The authors declare no competing interests.

\section{References}

1. Bryan $\mathrm{S}$ et al (2018) Cancer in Canada: stage at diagnosis. Health Rep Stat Can 29:21-25

2. Leslie A, Carey FA, Pratt NR, Steele RJC (2002) The colorectal adenoma \pm carcinoma sequence. Journal of British Surgery 89:845-860. https://doi.org/10.1046/j.1365-2168.2002.02120.x

3. Armaghany T, Wilson JD, Chu Q, Mills G (2012) Genetic alterations in colorectal cancer. Gastrointest Cancer Res 5:19-25

4. Fearon E, Vogelstein B (1990) A genetic model for colorectal tumorigenesis. Cell 61:759-767. https://doi.org/10.1016/00928674(90)90186-I

5. Smith LK, Pope C, Botha JL (2005) Patients' help-seeking experiences and delay in cancer presentation: a qualitative synthesis. Lancet 366:825-831. https://doi.org/10.1016/S0140-6736(05)67030-4

6. Forbes LJL, Warburton F, Richards MA, Ramirez AJ (2014) Risk factors for delay in symptomatic presentation: a survey of cancer patients. Br J Cancer 111:581-588. https://doi.org/10.1038/bjc. 2014.304

7. Alberta Health Services (2019) The 2019 report on cancer statistics in Alberta. Edmonton: Cancer Control Alberta. Alberta Health Services. https://www.albertahealthservices.ca/cancer/ Page1774.aspx. Accessed 24 Dec 2020

8. Vega P, Valentín F, Cubiella J (2015) Colorectal cancer diagnosis: pitfalls and opportunities. World J Gastrointest Oncol 7:422433. https://doi.org/10.4251/wjgo.v7.i12.422

9. Cappell MS (2008) Pathophysiology, clinical presentation, and management of colon cancer. Gastroenterol. Clin North Am 37:1-24. https://doi.org/10.1016/j.gtc.2007.12.002

10. John SKP, George S, Primrose JN, Fozard JBJ (2011) Symptoms and signs in patients with colorectal cancer. Colorectal Dis 13:1725. https://doi.org/10.1111/j.1463-1318.2010.02221.x

11. von Elm E, Altman DG, Egger M, Pocock SJ, Gøtzsche PC, Vandenbroucke JP (2014) The strengthening the reporting of observational studies in epidemiology (STROBE) statement: 
guidelines for reporting observational studies. Int J Surg 12:1495-1499. https://doi.org/10.1016/j.ijsu.2014.07.013

12. Selvachandran SN, Hodder RJ, Ballal MS, Jones P, Cade D (2002) Prediction of colorectal cancer by a patient consultation questionnaire and scoring system: a prospective study. Lancet 360:278 283. https://doi.org/10.1016/S0140-6736(02)09549-1

13. R Core Team (2013) R: A language and environment for statistical computing. R Foundation for Statistical Computing, Vienna, Austria [Online]. Available: http://www.R-project.org/

14. Safari S, Baratloo A, Elfil M, Negida A (2016) Evidence based emergency medicine; part 5 receiver operating curve and area under the curve. Emerg (Tehran) 4:111-113

15. Tinmouth $\mathbf{J}$ et al (2021) Estimating the backlog of colonoscopy due to coronavirus disease 2019 and comparing strategies to recover in Ontario, Canada. Gastroenterology 160:1400-1402. e1. https://doi.org/10.1053/j.gastro.2020.11.048

16. Rutter MD, Brookes M, Lee TJ, Rogers P, Sharp L (2021) Impact of the COVID-19 pandemic on UK endoscopic activity and cancer detection: a National Endoscopy Database Analysis. Gut 70:537543. https://doi.org/10.1136/gutjnl-2020-322179

17. Khan A, Bilal M, Morrow V, Cooper G, Thakkar S, Singh S (2021) Impact of the coronavirus disease 2019 pandemic on gastrointestinal procedures and cancers in the United States: a multicenter research network study. Gastroenterology 160:2602-2604. e5. https://doi.org/10.1053/j.gastro.2021.02.055

18. Robertson $\mathrm{R}$ et al (2006) Predicting colorectal cancer risk in patients with rectal bleeding. Br J Gen Pract 56:763-767

19. Ellis BG, Thompson MR (2005) Factors identifying higher risk rectal bleeding in general practice. Br J Gen Pract 55:949-955

20. Del Giudice ME, Vella ET, Hey A, Simunovic M, Harris W, Levitt C (2014) Systematic review of clinical features of suspected colorectal cancer in primary care. Can Fam Physician 60:e405-e415

21. Olde Bekkink M, McCowan C, Falk GA, Teljeur C, Van de Laar FA, Fahey T (2010) Diagnostic accuracy systematic review of rectal bleeding in combination with other symptoms, signs and tests in relation to colorectal cancer. Br J Cancer 102:48-58. https://doi.org/10.1038/sj.bjc.6605426

22. Sharara N, Nolan S, Sewitch M, Martel M, Dias M, Barkun AN (2016) Assessment of a colonoscopy triage sheet for use in a province-wide population-based colorectal screening program. Can J Gastroenterol Hepatol 2016:1-8. https://doi.org/10.1155/ 2016/4712192

23. Heitman SJ, Ronksley PE, Hilsden RJ, Manns BJ, Rostom A, Hemmelgarn BR (2009) Prevalence of adenomas and colorectal cancer in average risk individuals: a systematic review and metaanalysis. Clin Gastroenterol Hepatol 7:1272-1278. https://doi.org/ 10.1016/j.cgh.2009.05.032

24. Giacosa A, Frascio F, Munizzi F (2004) Epidemiology of colorectal polyps. Tech. Coloproctology 8:s243-s247. https://doi.org/10. 1007/s10151-004-0169-y

25. Guillem JG, Forde KA, Treat MR, Neugut AI, Bodian CA (1987) The impact of colonoscopy on the early detection of colonic neoplasms in patients with rectal bleeding. Ann Surg 208:606-611. https://doi.org/10.1097/00000658-198711000-00009

26. Adelstein B-A, Macaskill P, Chan SF, Katelaris PH, Irwig L (2011) Most bowel cancer symptoms do not indicate colorectal cancer and polyps: a systematic review. BMC Gastroenterol 11:65. https://doi.org/10.1186/1471-230X-11-65

27. Hamilton W, Round A, Sharp D, Peters TJ (2005) Clinical features of colorectal cancer before diagnosis: a population-based casecontrol study. Br J Cancer 93:399-405. https://doi.org/10.1038/ sj.bjc. 6602714

28. Semigran HL, Linder JA, Gidengil C, Mehrotra A (2015) Evaluation of symptom checkers for self diagnosis and triage: audit study. BMJ 351:h3480. https://doi.org/10.1136/bmj.h3480

Publisher's Note Springer Nature remains neutral with regard to jurisdictional claims in published maps and institutional affiliations. 